\title{
Pattern of Expression of the Uterine Milk Protein Gene and its Association with Productive Life in Dairy Cattle
}

\author{
H. Khatib, ${ }^{1}$ V. Schutzkus, Y. M. Chang, and G. J. M. Rosa \\ Department of Dairy Science, University of Wisconsin, Madison 53706
}

\begin{abstract}
The uterine milk proteins (UTMP) are the major proteins secreted by the endometrium, primarily under the control of progesterone. Specific functions of UTMP are poorly understood, but may include protease inhibition, nutrition of the conceptus, growth control, and suppression of the maternal immune system. The uterine milk protein gene (UTMP) was chosen for this study because of its possible roles in health traits and results of previous studies on the association of the UTMP region with milk production and productive life in dairy cattle. Expression of UTMP was examined in 198 bovine tissues obtained from 10 fetuses and 17 cows. Transcripts of UTMP were found in all cotyledon tissues examined and to a lesser extent in ovary, pituitary, and spleen tissues obtained from fetuses. The UTMP gene was predominantly expressed in endometrium (17/17), ovary (15/16), and caruncle (12/12) tissues obtained from cows. The predominant expression of UTMP in reproductive tissues is consistent with an important role of this gene in reproductive success. To investigate the association between UTMP and production traits in cattle, we identified 2 synonymous single nucleotide polymorphisms (SNP) at positions $1179(\mathrm{~A} / \mathrm{G})$ and 1296 $(\mathrm{A} / \mathrm{G})$ using the pooled DNA sequencing approach. The DNA was extracted from 28 Holstein sires and their 1,362 sons obtained from the Cooperative Dairy DNA Repository and from 913 cows from the University of Wisconsin resource population. Single nucleotide polymorphism 1296 was associated with a significant increase in productive life in both populations. This finding is similar to results previously obtained for the protease inhibitor gene, which is near UTMP and was also found to be associated with productive life in dairy cattle. Differential allelic expression of UTMP was observed in reproductive tissues obtained from 9 heterozygous individuals. The differential allelic expression observed in this study is consistent with other studies
\end{abstract}

Received November 1, 2006.

Accepted January 9, 2007.

${ }^{1}$ Corresponding author: hkhatib@wisc.edu showing a correlation between allelic variation in gene expression and phenotypic variability.

Key words: uterine milk protein gene, differential allelic expression, candidate gene, productive life

\section{INTRODUCTION}

The uterine milk proteins (UTMP) are the major proteins secreted by the endometrium, primarily under the control of progesterone (Moffatt et al., 1987). Specific functions of UTMP are poorly understood, but may include protease inhibition, nutrition of the conceptus, growth control, and suppression of the maternal immune system (Ing and Roberts, 1989). Stewart et al. (2000) showed that ovine intracaruncular endometrial UTMP mRNA levels increased about 3-fold between d 20 and 60 of gestation, increased another 3 -fold between d 60 and 80, and then declined slightly to d 120 . When using Western blotting and immunohistochemistry, goat UTMP has been localized to the glandular epithelium of the endometrium at d 25 of pregnancy (Tekin et al., 2005). Leslie et al. (1990) found that UTMP was detected in the uterine fluid and secreted by the endometrium of pregnant cows. However, at present, it is not known whether the bovine UTMP gene is expressed in bovine tissues other than the endometrium. Our study aimed to investigate the distribution of UTMP transcripts in a wide range of fetal and adult bovine tissues.

The UTMP gene was chosen for this study because previous studies of the UTMP region have shown an association with productive life (PL) and milk composition traits in dairy cattle. Heyen et al. (1999) reported an association between marker ILSTS054 and PL in the North American Holstein population. Khatib et al. (2005) reported a significant association between the protease inhibitor gene $(\boldsymbol{P I})$ and PL and milk composition traits in Holstein dairy cattle. In addition, both PI and UTMP have protease-inhibition functions, and the genes are both located on chromosome 21, within a $321.6-\mathrm{kb}$ genomic region. Thus, possible roles of UTMP in health traits and its proximity to $P I$ were the motives for investigation of possible effects of UTMP on health traits in dairy cattle. 
Recent studies in humans (Yan et al., 2002; Bray et al., 2003; Lo et al., 2003; Pastinen et al., 2003), in mice (Cowles et al., 2002), and in corn (Guo et al., 2004) have shown that alleles of nonimprinted genes are not expressed equally at the mRNA level, and such differential allelic expression (DAE) may be the basis for variation in disease susceptibility and in determining phenotypic diversity. Yan et al. (2002) examined single nucleotide polymorphisms (SNP) for 13 genes in 96 individuals and found significant differences in allelic variation in 6 out of the 13 genes studied, with 1.3- to 4.3-fold differences between alleles. In a survey of allelic variation among human genes, Pastinen et al. (2003) selected 129 genes based on their potential function in the immune system and metabolic disorders and identified $18 \%$ of the genes with deviations from the equimolar ratio between the 2 alleles. Lo et al. (2003) examined allele-specific gene expression of 1,063 transcribed SNP by using the Affymetrix HuSNP chip system. The authors found that among the 602 genes that were heterozygous, 326 showed preferential expression of 1 allele in at least 1 individual, and 170 of those genes showed a greater than 4-fold difference between the 2 alleles.

Accumulating evidence indicates that DAE is associated with phenotypic variability of quantitative and qualitative traits. For example, Hirota and colleagues (2004) studied the relationship between DAE of the human cytochrome P450 3A4 (CYP3A4) gene and metabolic activity in the liver. Individuals with a large difference in expression levels between the 2 alleles showed reduced total CYP3A4 mRNA and, hence, the total metabolic activity of the gene was reduced. That was the first study to demonstrate that CYP3A4 expression levels were affected by allele-specific expression levels.

In this study, we analyzed the expression pattern of $U T M P$ in fetal and adult cattle tissues and investigated its association with production traits in 2 independent Holstein populations. In addition, we examined the relationship between DAE of UTMP and association with quantitative traits.

\section{MATERIALS AND METHODS}

\section{Tissue Collection and Nucleic Acid Extraction}

Tissues from 10 fetuses and 17 pregnant cows were obtained from a local slaughterhouse. For 9 of 10 fetuses, their dams were included in this study. Fetal tissues included lung, brain, bone, eye, heart, skeletal muscle, liver, cotyledon, spleen, pituitary, kidney, intestine, pancreas, mammary gland, testis, ovary, hypothalamus, and cartilage. The fetuses were from 55 to $100 \mathrm{~d}$ postconception. The tissues from cows included endometrium, ovary, oocytes, liver, heart, spleen, kid- ney, caruncle, pancreas, lung, and skeletal muscle. After dissection, tissues were immediately chilled on ice and submerged in RNALater RNA stabilizing reagent (Qiagen, Valencia, CA). Total RNA was extracted using the RNeasy kit (Qiagen) and treated with DNase I (Sigma, St Louis, MO). Then, DNA was extracted by grinding 30 to $100 \mathrm{mg}$ of one tissue from each individual using the AquaPure Genomic DNA kit (Bio-Rad, Hercules, CA).

\section{Reverse Transcription PCR}

Reverse transcription (RT) of the bovine UTMP gene was performed using the primers UMP1 (ATGTCCCA CGGGAGAATGAA) and UMP2 (CCTCCTTCTGGGTG AGTTTG). The temperature cycles were as follows: $50^{\circ} \mathrm{C}$ for $30 \mathrm{~min}$ (reverse transcription); $95^{\circ} \mathrm{C}$ for 15 min, followed by 33 cycles of $94^{\circ} \mathrm{C}$ for $1 \mathrm{~min}, 58^{\circ} \mathrm{C}$ for $1 \mathrm{~min}, 72^{\circ} \mathrm{C}$ for $1 \mathrm{~min}$; and a final extension at $72^{\circ} \mathrm{C}$ for $10 \mathrm{~min}$. Primers $\beta$-actinF (CAGCACAATGAAGAT CAAGATCATC) and $\beta$-actinR (AAAGGGTGTAACGC AGCTAACAGT) were used to amplify $191 \mathrm{bp}$ from the housekeeping gene $\beta$-actin (GenBank accession number NM_173979) cDNA. The RT-PCR products were electrophoresed on a $1.5 \%$ agarose gel. The detectable amplification of any product was interpreted as a positive indication of UTMP expression; no formal quantitative test was performed. Primers $\beta$-actinF and $\beta$-actinR were used to amplify the housekeeping gene $\beta$-actin as a control for the expression of UTMP in the various tissues.

\section{Phenotypic Data}

The association between $U T M P$ variants and production traits was studied in 2 independent Holstein populations: the Cooperative Dairy DNA Repository (CDDR) population of AI sires and cows from the University of Wisconsin resource population (henceforth, UW resource population). The UW population was created to search (using a daughter design) for genetic markers in association with susceptibility to paratuberculosis. The 12 sire families of this population were chosen from a large number of candidate bulls with large numbers of daughters in production in 2000. Criteria for the final selection of the 12 bulls included having large numbers of daughters in production and relatively low pedigree relationships among the chosen bulls to more broadly sample the chromosomes of the US Holstein population. Phenotypic data for both analyses were obtained from the Animal Improvement Programs Laboratory (Beltsville, MD). The CDDR data were PTA for milk yield, milk protein and fat yields, milk protein and fat percentages, PL in months, and 
SCS from August 2005. The phenotypic data from the UW resource population comprised yield deviations for milk yield, milk protein and fat yields, and PL. Productive life is a longevity trait defined as a cow's total lifetime months in milk with limits of 10 mo per lactation and $7 \mathrm{yr}$ of age (VanRaden and Wiggans, 1995). Deviated records of PL were based on direct observations and also correlated traits measured earlier in life. The average reliability of PTA for PL in the CDDR population was $71 \%$.

\section{Polymorphism Detection and Genotyping}

Semen samples from 28 Holstein sires and their 1,362 sons (23 to 104 sons per sire) were obtained from the CDDR, which is maintained by the USDA Bovine Functional Genomics Laboratory. In addition, blood samples were obtained from 913 cows from the UW resource population. For a detailed description of this population, see Cobanoglu et al. (2006). Genomic DNA was extracted from semen and blood samples using standard procedures. To detect SNP in the UTMP gene (GenBank accession number L22095), DNA pools were constructed from 220 bovine samples and amplified with the primers UTMP3 (GGCCCTACATCAAGCTG AGA) and UTMP4 (CTACTCAACTTGGGGGTTGA) as previously described (Leonard et al., 2005). The PCR products of the pooled DNA samples were sequenced and SNP were identified by visually inspecting sequence traces. For individual genotyping, primers UTMP3 and UTMP4 were used to amplify a 327-bp fragment of UTMP from genomic DNA. The PCR products were subjected to RFLP detection using the restriction enzyme BsrI that distinguishes alleles $\mathrm{A}$ and $\mathrm{G}$ of the SNP at position 1296. The digestion products were electrophoresed on a $3.0 \%$ agarose gel.

\section{Allele Expression Quantification}

Differential allelic expression of the UTMP gene was quantified by a sequencing-based approach and by single-nucleotide primer extension analysis. In the sequencing approach, RT-PCR products amplified from heterozygous individuals were sequenced according to standard procedures. Sequencing reactions of PCR amplicons were performed for 50 cycles at $96^{\circ} \mathrm{C}$ for $10 \mathrm{~s}$, $58^{\circ} \mathrm{C}$ for $4 \mathrm{~min}$, and a final extension at $72^{\circ} \mathrm{C}$ for 7 min. Data were analyzed using Applied Biosystems' Sequencing Analysis (version 5.0; Applied Biosystems, Foster City, CA). The SNP were identified by visually inspecting each base in sequencing traces. Allelic variation was estimated by measuring the proportions of the peak heights of the 2 alternative alleles of the SNP. In the primer extension approach (Norton et al., 2002),
RT-PCR products were purified from agarose gel using the GFX PCR DNA purification Kit (Amersham Biosciences, Piscataway, NJ). Primer extension reactions were prepared in a total volume of $10 \mu \mathrm{L}$ containing 1 $\mu \mathrm{L}$ of purified RT-PCR product, $5 \mu \mathrm{L}$ of SnaPshot Kit (Applied Biosystems), $0.02 \mu M$ of extension primer, and $1 \mu \mathrm{L}$ of deionized water. The primer extension reactions were subjected to 25 cycles of $96^{\circ} \mathrm{C}$ for $10 \mathrm{~s}, 50^{\circ} \mathrm{C}$ for 5 $\mathrm{s}$, and $60^{\circ} \mathrm{C}$ for $30 \mathrm{~s}$. In a postextension treatment, reactions were treated with 1 unit of shrimp alkaline phosphatase at $37^{\circ} \mathrm{C}$ for $1 \mathrm{~h}$ followed by deactivation of the enzyme at $75^{\circ} \mathrm{C}$ for $15 \mathrm{~min}$. The primer 1179.ext (GTGAAGGCAAAGGAGGTCCC) was used in the primer extension reactions. Samples were electrophoresed on a 3700 DNA sequencer (PE Applied Biosystems) and data were analyzed by using Genescan Analyzer version 2.5 software (PE Applied Biosystems). Allelic ratios were estimated by measuring the proportions of the peak heights of the 2 fluorescently labeled variants of the SNP found at the same position. No significance tests were performed.

\section{Statistical Analysis}

For the CDDR population, data relative to each trait were analyzed using an allele substitution model expressed as

$$
\mathrm{y}_{\mathrm{ij}}=\mu+\mathrm{s}_{\mathrm{i}}+\beta \mathrm{x}_{\mathrm{ij}}+\varepsilon_{\mathrm{ij}},
$$

where $y_{i j}$ is the PTA value relative to son $j$ of sire $i, \mu$ is a general constant (intercept), $\mathrm{s}_{\mathrm{i}}$ is the fixed effect of sire i, $\beta$ is the regression coefficient representing half of the allele substitution effect $(\alpha / 2), \mathrm{x}_{\mathrm{ij}}$ is the number of $\mathrm{G}$ alleles $(0,1$, or 2$)$ on son $\mathrm{j}$ of sire $\mathrm{i}$, and $\varepsilon_{\mathrm{ij}}$ is a residual term. Reliabilities of the sons' PTA were incorporated as weights in the model to obtain weighted least squares estimates of the allele substitution effects.

Data relative to the daughters in the UW resource population were analyzed using 2 models. First, an allele substitution model similar to the CDDR described above was considered, which is expressed as

$$
\mathrm{y}_{\mathrm{ijk}}=\mu+\mathrm{s}_{\mathrm{i}}+\mathrm{p}_{\mathrm{ij}} \tau+\beta \mathrm{x}_{\mathrm{k}}+\varepsilon_{\mathrm{ijk}},
$$

where $\mathrm{y}_{\mathrm{ijk}}$ represents the yield deviation of daughter $\mathrm{j}$ of sire i, $\tau$ is an effect associated with Mycobacterium paratuberculosis infection status, and $\mathrm{p}_{\mathrm{ij}}$ is an indicator variable assuming the values 0 and 1 for noninfected and infected cows, respectively. The index $\mathrm{k}$ indicates the genotype of the cows $(\mathrm{k}=\mathrm{AA}, \mathrm{AG}$, or $\mathrm{GG})$, and $\mathrm{x}_{\mathrm{k}}$ is the number of $\mathrm{G}$ alleles in the genotype $\mathrm{k}\left(\mathrm{x}_{\mathrm{k}}=0,1\right.$, or 2 , respectively). The remaining terms in the model are as previously defined. Mycobacterium paratubercu- 
Table 1. Expression pattern of uterine milk protein gene (UTMP) transcripts obtained from various fetal tissues ${ }^{1}$

Fetus

(age in d) Tissues expressing UTMP

Tissues not expressing UTMP

$1(55)$

$2(65)$

$3(68)$

$4(68)$

$5(70)$

$6(70)$

$7(75)$

$8(85)$

$9(90)$

$10(100)$
Cotyledon, pituitary

Cotyledon

Cotyledon

Cotyledon

Ovary, pituitary, hypothalamus, spleen
Eye, heart, muscle, liver, lung, brain, bone

Spleen, eye, lung, heart, kidney, intestine, pancreas, muscle, liver, bone, brain, mammary gland Heart, muscle, eye, spleen, bone, lung, liver, kidney, testis, pituitary, pancreas, brain Mammary gland Heart, muscle, brain, spleen, ovary

Liver, lung, brain, muscle, intestine, eye, bone, heart, kidney, ovary, pancreas, mammary gland Lung, brain, eye, bone, testis, heart, kidney, muscle, pituitary, spleen, liver

Pituitary, spleen, lung, heart, brain, kidney, liver, muscle, adrenal, mammary gland, ovary Kidney

Lung, heart, pancreas, kidney, liver, bone, cartilage, mammary gland, muscle

${ }^{1}$ Not all tissue types were examined in all fetuses.

losis infection status was included in the model because the UW population was originally created to search for genetic markers associated with susceptibility to paratuberculosis.

In addition, a second model was used for each trait, which is described as

$$
\mathrm{y}_{\mathrm{ijk}}=\mu+\mathrm{s}_{\mathrm{i}}+\mathrm{p}_{\mathrm{ij}} \tau+\mathrm{g}_{\mathrm{k}}+\varepsilon_{\mathrm{ijk}},
$$

where $\mathrm{g}_{\mathrm{k}}$ is the effect of the UTMP genotype $\mathrm{k}$. Additive genetic effects were estimated as half the difference between the 2 homozygous groups, and dominance effects were estimated as the difference between the average of the 2 homozygous groups and the heterozygous group. The AA genotype was set as baseline for estimating the genotypic effects. All the analyses were implemented using the GLM procedure of SAS (SAS Institute, 1999).

\section{RESULTS}

\section{Tissue Distribution of UTMP Expression in Fetuses and Cows}

Table 1 shows the expression of UTMP in 93 fetal tissues. The UTMP gene was expressed in all 5 cotyledon tissues examined. Two pituitary tissues expressed $U T M P ; 1$ tissue from fetus 2 ( $\mathrm{d} 65)$ showed a low expression level. Ovary, hypothalamus, and spleen tissues showed low levels of expression in fetus 10 (d 100). Expression of UTMP was not detected in eye, heart, skeletal muscle, lung, bone, kidney, pancreas, testis, mammary gland, adrenal, or intestine tissues in any of the fetuses examined. Table 2 shows the expression status of UTMP in 107 tissues obtained from 17 cows; UTMP was predominantly expressed in endometrium (17/17), ovary (15/16), and caruncle (12/12) tissues. Inconsistent amplification of UTMP was shown in liver, oocytes, spleen, and lung tissues. The UTMP gene was expressed in the livers of 3 cows out of 6 examined; 2 liver tissues showed low expression levels; UTMP was also expressed in 1 oocyte tissue out of 12 examined. Heart, skeletal muscle, kidney, and pancreas tissues did not express the UTMP gene in any examined individual.

\section{Association of UTMP with Productive Life in Two Independent Holstein Populations}

Using the pooled DNA sequencing approach, an $\mathrm{A} / \mathrm{G}$ SNP at position 1179 and an A/G SNP at position 1296 were identified in bovine UTMP. Genotyping of random samples revealed low polymorphism at SNP 1179; therefore, it was not further analyzed in this study. For SNP 1296, the frequencies of allele G in the CDDR and UW populations were 0.72 and 0.64 , respectively. The association between UTMP variants at position 1296 and production traits was tested in 1,363 bulls from the CDDR and in 913 cows from the UW resource Holstein dairy cattle populations. Single nucleotide polymorphism 1296 was associated with a significant increase in PL in both populations. For the CDDR population, allele $\mathrm{G}$ was associated with a significant increase in PL $(P=0.008)$. Estimated allele substitution effects and their standard errors for production and health traits are given in Table 3. A bull inheriting allele $G$ vs. allele $\mathrm{A}$ is expected to have, on average, $0.26 \mathrm{mo}$ greater PTA for PL. For the UW resource population, allele $\mathrm{G}$ had an average substitution effect of $1.44 \mathrm{mo}$ of PL $(P=0.033)$. The UTMP variants did not show significant associations with milk, fat, or protein yields or SCS in either population studied (Table 3). Dominance and additive genetic effects were estimated for PL and other traits using the UW resource population data. Dominance effects were not statistically significant for any trait. An additive genetic effect was significant only for PL $(P=0.049)$, with an estimate of 1.34 $\pm 0.68 \mathrm{mo}$. 
Table 2. Expression pattern of uterine milk protein gene (UTMP) transcripts obtained from various pregnant cows' tissues ${ }^{1}$

Cow (estimated d into gestation)

$1(100)$

$2(100)$

$3(85)$

$4(70)$

$5(55)$

$6(75)$

$7(68)$

$8(65)$

$9(90)$

$10(68)$

$11(90)$

$12(85)$

$13(83)$

$14(90)$

$15(75)$

$16(125)$

$17(80)$
Tissues expressing UTMP

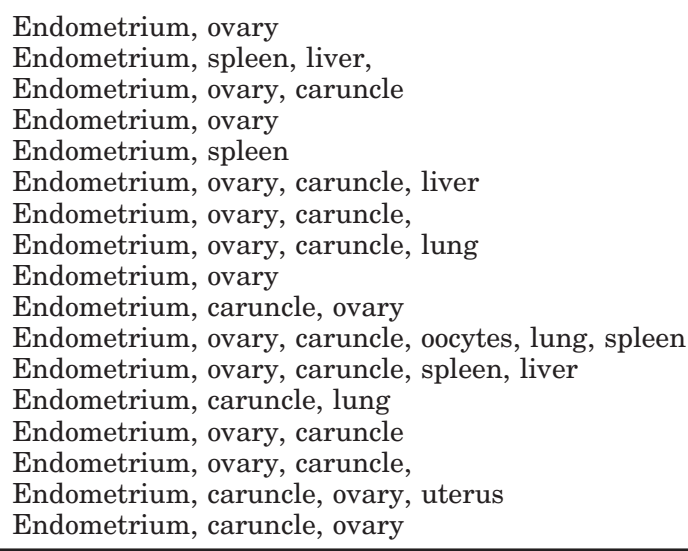

Endometrium, spleen, liver,

Endometrium, ovary, caruncle

Endometrium, ovary

Endometrium, spleen

Endometrium, ovary, caruncle, liver

Endometrium, ovary, caruncle,

Endometrium, ovary, caruncle, lung

Endometrium, ovary

Endometrium, caruncle, ovary

Endometrium, ovary, caruncle, oocytes, lung, spleen

Endometrium, ovary, caruncle, spleen, liver

Endometrium, caruncle, lung

Endometrium, ovary, caruncle

Endometrium, ovary, caruncle,

Endometrium, caruncle, ovary, uterus

Endometrium, caruncle, ovary

Tissues not expressing UTMP

Heart, kidney
Heart, ovary, oocytes, kidney, lung
Spleen, kidney
Oocytes, pancreas, lung
Liver, heart, muscle, oocytes, ovary, lung
Heart, kidney, oocytes, spleen
Muscle, liver, lung, oocytes, heart, spleen
Heart, muscle, liver, oocytes, pancreas
Oocytes
Oocytes
Pancreas
Heart, muscle, oocytes, pancreas, lung
Oocytes, lung, pancreas
Oocytes, lung, pancreas
Heart, muscle, kidney
Heart, muscle

${ }^{1}$ Not all tissues types were examined in all cows.

\section{Allelic Variation in UTMP Gene Expression}

To detect heterozygous individuals for allelic variation analysis, primers UMP3 and UMP4 were used to amplify genomic DNA from 10 fetuses and 17 cows. Fetus 10 and cow 11 were heterozygous for the SNP $(\mathrm{A} / \mathrm{G})$ at position 1179 , and 5 cows (cows $2,8,12,16$, and 17) were heterozygous for the $\operatorname{SNP}(\mathrm{A} / \mathrm{G})$ at position 1296. Then, primers UMP1 and UMP2 were used to amplify RT-PCR products from endometrium, ovary, and caruncle tissues obtained from the informative individuals. Differential allelic expression was measured in tissues in which UTMP was highly expressed. Table 4 shows DAE of UTMP at SNP 1296 in these tissues, as measured by allelic ratios of G/A. The UTMP gene displayed DAE in all heterozygous individuals examined. Allele G seemed to be preferentially expressed in all endometrium tissues, although no formal statistical test was performed to evaluate the significance of this result. Extreme DAE was observed for 2 of 3 ovary tissues (monoallelic expression) and for 2 of 4 caruncle tissues (G/A allelic ratios of 2.50 and 4.00).

\section{DISCUSSION}

In this study we report the expression pattern of the bovine UTMP gene in fetal and adult tissues and the association with production traits in 2 independent dairy cattle populations. The UTMP gene was chosen for this study because of its possible roles in health traits and previous results showing an association of the UTMP region with milk production and PL in dairy cattle.

This is the first report on expression analysis of UTMP transcripts in a wide range of cattle tissues. Expression of UTMP was examined in a total of 198 tissues obtained from 10 fetuses and 17 pregnant cows. Transcripts of UTMP were found in all cotyledon tissues examined and to a lesser extent in ovary, pituitary, and spleen fetal tissues. The UTMP transcripts were not

Table 3. Estimates of the allele substitution effect (of allele G) and standard errors for production and health traits in the CDDR and UW populations ${ }^{1}$

\begin{tabular}{|c|c|c|c|c|}
\hline \multirow[b]{2}{*}{ Trait } & \multicolumn{2}{|c|}{ CDDR } & \multicolumn{2}{|c|}{ UW } \\
\hline & Estimate (SE) & $P$-value & Estimate (SE) & $P$-value \\
\hline Fat yield & $-0.188(1.894)$ & 0.920 & $-0.081(4.30)$ & 0.985 \\
\hline Fat percentage & $0.004(0.008)$ & 0.573 & $\mathrm{NR}^{2}$ & \\
\hline Milk yield & $-33.14(51.52)$ & 0.520 & $-120.7(115.2)$ & 0.295 \\
\hline Protein yield & $-1.520(1.290)$ & 0.237 & $-2.093(3.045)$ & 0.492 \\
\hline Protein percentage & $-0.002(0.016)$ & 0.529 & NR & \\
\hline SCS & $-0.016(0.014)$ & 0.236 & $0.065(0.067)$ & 0.336 \\
\hline Productive life & $0.260(0.098)$ & 0.008 & $1.443(0.675)$ & 0.033 \\
\hline
\end{tabular}

${ }^{1}$ Populations: CDDR = Cooperative Dairy DNA Repository; UW resource population = University of Wisconsin resource population.

${ }^{2} \mathrm{NR}=$ no records available for these traits. 
Table 4. Expression ratios of G/A alleles at single nucleotide polymorphism 1296 of the uterine milk protein gene (UTMP) in 5 heterozygous individuals for ovary, endometrium, and caruncle tissues

\begin{tabular}{llcc}
\hline & \multicolumn{3}{c}{ Allelic ratio } \\
\cline { 2 - 4 } Cow & Ovary & Endometrium & Caruncle \\
\hline M2 & $\mathrm{G}^{1}$ & 1.96 & $\mathrm{ND}^{2}$ \\
M8 & $\mathrm{ND}$ & 1.27 & 0.51 \\
M12 & $\mathrm{G}^{1}$ & 1.78 & 4.00 \\
M16 & ND & 1.81 & 1.56 \\
M17 & 0.50 & 1.81 & 2.30 \\
\hline
\end{tabular}

${ }^{1}$ Monoallelic expression of allele $\mathrm{G}$.

${ }^{2} \mathrm{ND}=$ not done.

found in any other fetal tissues examined. To exclude the possibility of RT-PCR reaction failure in tissues where $U T M P$ expression was not observed, the $\beta$-actin gene was amplified for all tissues. Expression of the $\beta$ actin gene was detected in all examined tissues. However, we cannot exclude the possibility of variable expression of $\beta$-actin among the different tissues or individuals examined. Although the expression of UTMP in fetal tissues was surprising, its presence in reproductive tissues (cotyledon and ovary) might shed more light on the role of this gene in maintenance of pregnancy and fetal survival. Roberts and Bazer (1988) suggested that nutrition of the conceptus, growth control, and immunosuppression of the local maternal system are possible functions of the UTMP.

The expression of UTMP has been mainly studied in sheep, with only a few studies on expression and localization of the bovine gene. In sheep, UTMP is the predominant protein present in the uterine fluid from d 30 of pregnancy until term (Moffatt et al., 1987); UTMP mRNA is not detected in endometrium until d 14 of pregnancy (Ing and Roberts, 1989). In addition, mRNA levels of ovine UTMP have been found to be affected by day of pregnancy (Stewart et al., 2000).

In this study, bovine UTMP was predominantly expressed in endometrium, ovary, and caruncle tissues in pregnant cows. Inconsistent amplification of RT-PCR products was observed in oocytes, lung, liver, and spleen tissues. On the other hand, heart, muscle, and pancreas tissues did not express UTMP in any examined individual. Thus, the predominant expression of UTMP in reproductive tissues is consistent with an important role for this protein in reproductive success as previously suggested for the ovine gene (Ing and Roberts, 1989). However, in contrast to the aforementioned studies, this is the first report on expression of UTMP in tissues other than endometrium.

In this study, we aimed to investigate the association between UTMP and milk production traits and PL in dairy cattle. To do this, we identified 2 synonymous
SNP at positions $1179(\mathrm{~A} / \mathrm{G})$ and $1296(\mathrm{~A} / \mathrm{G})$ using the pooled DNA sequencing approach (Kwok et al., 1994; Khatib et al., 2006). The SNP at position 1296 was associated with a significant increase in PL. This finding parallels results previously obtained for the PI locus, which was also found to be associated with PL in dairy cattle (Heyen et al., 1999; Khatib et al., 2005). Taken together, these results provide strong evidence that the UTMP region is associated with the PL trait in dairy cattle. Unfortunately, these studies are not able to determine whether the effect observed is due to polymorphism in PI, UTMP, or another locus in that region. Additional research on this topic should be undertaken.

There is accumulating evidence that allelic variation in gene expression is correlated with phenotypic variability of quantitative and qualitative traits. In humans, only a few studies have addressed the possible roles of allele-specific expression in phenotypic variability among individuals and in disease susceptibility (Duno et al., 2004; Hirota et al., 2004; Murakami et al., 2004). For example, Duno et al. (2004) examined DAE of the CLCN1 gene, which causes myotonia congenita, an inherited disorder characterized by delayed skeletal muscle relaxation. Interestingly, they found that the expression level of the mutant allele was higher than that of the wild-type allele, and they suggested that differential expression of CLCN1 alleles might have roles in progression of myotonia congenital disease.

In this study, a polymorphism-based approach was used to analyze the allelic variation in expression of the bovine UTMP gene in reproductive tissues obtained from 9 heterozygous individuals. Reverse transcriptionPCR analysis revealed that UTMP is expressed mainly in ovary, endometrium, and caruncle tissues. The DAE of UTMP in these tissues was measured as an allelic ratio of G/A alleles at SNP 1296. All heterozygous individuals examined displayed DAE, with allele G preferentially expressed in all endometrium tissues. Monoallelic expression (allele G) was observed in 2 of 3 ovary tissues and in 2 of 4 caruncle tissues. It is generally believed that genes displaying DAE would cause phenotypic variability across individuals. Given that UTMP has possible roles in health traits and based on the constant preferential expression of $\mathrm{G}$ allele at SNP 1296 , it is plausible that this SNP is linked to improved PL.

Thus, the DAE of the bovine UTMP gene observed in this study is consistent with other studies on different genes that have also shown a correspondence between allelic variation in gene expression and phenotypic variability.

In summary, in this study we report that UTMP is primarily expressed in the bovine endometrium, ovary, 
and caruncle tissues. Also, we report that UTMP SNP 1296 shows significant association with PL in 2 independent Holstein cattle populations. This SNP could be exploited by marker-assisted selection for genetic improvement of PL within a breeding nucleus or commercial population; or by marker-assisted introgression for transferring desired alleles from a resource population to a commercial population.

\section{ACKNOWLEDGMENTS}

This work was supported by start-up funding from the University of Wisconsin and by The Draper Technology Innovation Fund from Graduate School, the University of Wisconsin-Madison. We thank George E. Shook for providing DNA samples form the UW Resource population.

\section{REFERENCES}

Bray, N. J., P. R. Buckland, M. J. Owen, and M. C. O’Donovan. 2003. Cis-acting variation in the expression of a high proportion of genes in human brain. Hum. Genet. 113:149-153.

Cobanoglu, O., I. Zaitoun, Y. M. Chang, G. E. Shook, and H. Khatib. 2006. Effects of the signal transducer and activator of transcription 1 (STAT1) gene on milk production traits in Holstein dairy cattle. J. Dairy Sci. 89:4433-4437.

Cowles, C. R., J. N. Hirschhorn, D. Altshuler, and E. S. Lander. 2002. Detection of regulatory variation in mouse genes. Nat. Genet. 32:432-437.

Duno, M., E. Colding-Jorgensen, M. Grunnet, T. Jespersen, J. Vissing, and M. Schwartz. 2004. Difference in allelic expression of the CLCN1 gene and the possible influence on the myotonia congenita phenotype. Eur. J. Hum. Genet. 12:738-743.

Guo, M., M. A. Rupe, C. Zinselmeier, J. Habben, B. A. Bowen, and O. S. Smith. 2004. Allelic variation of gene expression in maize hybrids. Plant Cell 16:1707-1716.

Heyen, D. W., J. I. Weller, M. Ron, M. Band, J. E. Beever, E. Feldmesser, Y. Da, G. R. Wiggans, P. M. VanRaden, and H. A. Lewin. 1999. A genome scan for QTL influencing milk production and health traits in dairy cattle. Physiol. Genomics 1:165-175.

Hirota, T., I. Ieiri, H. Takane, S. Maegawa, M. Hosokawa, K. Kobayashi, K. Chiba, E. Nanba, M. Oshimura, T. Sato, S. Higuchi, and K. Otsubo. 2004. Allelic expression imbalance of the human CYP3A4 gene and individual phenotypic status. Hum. Mol. Genet. 13:2959-2969.

Ing, N. H., and R. M. Roberts. 1989. The major progesterone-modulated proteins secreted into the sheep uterus are members of the serpin superfamily of serine protease inhibitors. J. Biol. Chem. 264:3372-3379.
Khatib, H., E. Heifetz, and J. C. Dekkers. 2005. Association of the protease inhibitor gene with production traits in Holstein dairy cattle. J. Dairy Sci. 88:1208-1213.

Khatib, H., S. Leonard, V. Schutzkus, W. Luo, and Y. M. Chang. 2006. Association of the OLR1 gene with milk composition in Holstein dairy cattle. J. Dairy Sci. 89:1753-1760.

Kwok, P. Y., C. Carlson, T. D. Yager, W. Ankener, and D. A. Nickerson. 1994. Comparative analysis of human DNA variations by fluorescence-based sequencing of PCR products. Genomics 23:138-144.

Leonard, S., H. Khatib, V. Schutzkus, Y. M. Chang, and C. Maltecca. 2005. Effects of the osteopontin gene variants on milk production traits in dairy cattle. J. Dairy Sci. 88:4083-4086.

Leslie, M. V., P. J. Hansen, and G. R. Newton. 1990. Uterine secretions of the cow contain proteins that are immunochemically related to the major progesterone-induced proteins of the sheep uterus. Domest. Anim. Endocrinol. 7:517-526.

Lo, H. S., Z. Wang, Y. Hu, H. H. Yang, S. Gere, K. H. Buetow, and M. P. Lee. 2003. Allelic variation in gene expression is common in the human genome. Genome Res. 13:1855-1862.

Moffatt, J., F. W. Bazer, P. J. Hansen, P. W. Chun, and R. M. Roberts. 1987. Purification, secretion and immunocytochemical localization of the uterine milk proteins, major progesterone-induced proteins in uterine secretions of the sheep. Biol. Reprod. 36:419-430.

Murakami, Y., K. Isogai, H. Tomita, M. Sakurai-Yageta, T. Maruyama, A. Hidaka, K. Nose, K. Sugano, and A. Kaneko. 2004. Detection of allelic imbalance in the gene expression of hMSH2 or RB1 in lymphocytes from pedigrees of hereditary, nonpolyposis, colorectal cancer and retinoblastoma by an RNA difference plot. J. Hum. Genet. 49:635-641.

Norton, N., N. M. Williams, H. J. Williams, G. Spurlock, G. Kirov, D. W. Morris, B. Hoogendoorn, M. J. Owen, and M. C. O'Donovan. 2002. Universal, robust, highly quantitative SNP allele frequency measurement in DNA pools. Hum. Genet. 110:471-478.

Pastinen, T., R. Sladek, S. Gurd, A. Sammak, B. Ge, P. Lepage, K. Lavergne, A. Villeneuve, T. Gaudin, H. Brandstrom, A. Beck, A. Verner, J. Kingsley, E. Harmsen, D. Labuda, K. Morgan, M. C. Vohl, A. K. Naumova, D. Sinnett, and T. J. Hudson. 2003. A survey of genetic and epigenetic variation affecting human gene expression. Physiol. Genomics 16:184-193.

Roberts, R. M., and F. W. Bazer. 1988. The functions of uterine secretions. J. Reprod. Fertil. 82:875-892.

SAS Institute. 1999. SAS User's Guide. SAS OnlineDoc, Version 8. SAS Institute Inc., Cary, NC.

Stewart, M. D., G. A. Johnson, C. A. Gray, R. C. Burghardt, L. A. Schuler, M. M. Joyce, F. W. Bazer, and T. E. Spencer. 2000. Prolactin receptor and uterine milk protein expression in the ovine endometrium during the estrous cycle and pregnancy. Biol. Reprod. 62:1779-1789.

Tekin, S., M. B. Padua, G. R. Newton, and P. J. Hansen. 2005. Identification and cloning of caprine uterine serpin. Mol. Reprod. Dev. 70:262-270.

VanRaden, P. M., and G. R. Wiggans. 1995. Productive life evaluations: Calculation, accuracy, and economic value. J. Dairy Sci. 78:631-638.

Yan, H., W. Yuan, V. E. Velculescu, B. Vogelstein, and K. W. Kinzler. 2002. Allelic variation in human gene expression. Science 297:1143. 